\title{
Willingness to Pay for the Subscription Fee of Public Broadcasting System
}

\author{
Inho Park, Hyun Soon Park* \\ Department of Journalism \& Mass Communication, Sungkyunkwan University, Seoul, South Korea \\ Email: ${ }^{*}$ serenity@skku.edu
}

Received 10 January 2014; revised 12 February 2014; accepted 21 February 2014

Copyright (C) 2014 by authors and Scientific Research Publishing Inc.

This work is licensed under the Creative Commons Attribution International License (CC BY). http://creativecommons.org/licenses/by/4.0/

(c) (i) Open Access

\begin{abstract}
The study aims at developing communication strategies for the public broadcasting system according to WTP (Willingness to Pay) for the subscription fee and the audience's perception of the public broadcasting system as a public good. A quasi-experiment was conducted for audiences who have previously watched public broadcasting channels. According to the results, those respondents who think of public broadcasting as a public good and who think that public broadcasting performs its public role well have high intention to pay the subscription fee. Respondents feel at a loss when they pay the subscription fee, and the willingness to pay the fee goes down.
\end{abstract}

\section{Keywords}

Public Broadcasting System; Subscription Fee; WTP; Framing

\section{Introduction}

The present study focuses on how the public broadcasting system can resolve conflicts with its audience regarding subscription fee payment. The study aims at developing communication strategies for the public broadcasting system for its audiences according to WTP (Willingness to Pay) the subscription fee and audiences' perceptions about the public broadcasting system as a public good. In particular, the study adopted Kahneman \& Tversky's prospect theory in order to examine the effects of gain and loss framing on WTP for the public good.

The subscription fee is an important source of income that enables public broadcasting systems to better pursue public interests. The subscription fee is often taken for granted as a mandatory payment, like a tax. Although the stakeholders of public broadcasting maintain that the subscription fee should be required and increased, the majority of the public does not want to pay it. Political and academic approaches have not yet solved the controversy surrounding public broadcasting and the subscription fee in Korea.

The Korean Public Broadcasting System (KBS) has garnered considerable public controversy regarding the

"Corresponding author. 
public broadcasting subscription fee. Unlike registration and usage fees for cable TV, satellite TV, or IPTV, the public broadcasting system requires all the people who own a television to pay a public broadcasting subscription fee, similar in concept to a tax (Choe, 2010). The subscription fee for KBS has stayed at 2500 KRW (Korean Won, about \$2 US) per month since 1981, despite economic inflation. Over the last 10 years, KBS's attempts to rationalize the subscription fee have encountered objections by politicians and NGOs (Kim \& Lee, 2010). Even though it is viewers who pay the subscription fee, the issue has been discussed at large in the political arena (Kang, 2004a; Kang, 2006) but has not focused on public opinion about public broadcasting or its willingness to pay the subscription fee (Kim, 2008).

The subscription fee is a kind of monetary obligation collected to maintain the public broadcasting system; however, the fee is often characterized as a disadvantage or a loss for the public (Park, 2010). In the past, public broadcasting was treated as a public good (Samuelson, 1954, 1958. 1964). Meanwhile, due to changes in the new media environment, such as digitalization and convergence of broadcasting and telecommunication, the public broadcasting system in Korea has been complemented by several commercial channels offered by cable TV, satellite TV, and IPTV (Kang, 2004b). Therefore, the public broadcasting system in Korea is no longer considered a unique public good, which has increased the public's resistance to paying the subscription fee. As a result, $79.8 \%$ of Korean viewers and $47 \%$ of British public broadcasting viewers were found to oppose the subscription fee (Park, 2010). Accordingly, people who have different perceptions about public broadcasting may have different degrees of willingness to pay the subscription fee. In light of this situation, KBS has encountered difficulties in requiring the public to pay the subscription fee. Before raising the subscription fee, questions about viewer perceptions toward public broadcasting should be examined, because intention to pay the subscription fee may depend on whether or not the public perceives public broadcasting as a public good.

Few studies in Korea have examined the subscription fee from the public's perspective. Kim and Lee (2010) point out that there have been few attempts to make the public understand why they need to pay the subscription fee. Communication efforts to create social consent by informing the public about the importance of the subscription fee have been insufficient. An attempt is needed to analyze attitudes toward public broadcasting and intention to pay the subscription fee from the point of view of the public.

WTP is a method of measuring the value of a good by determining the maximum amount of money that people are willing to pay to acquire the good (Kahneman et al., 1993). It is considered to be an accurate and objective method because the answers are expressed in terms of a numeral index, money. This study examined the difference in WTP between people who perceive public broadcasting as a public good and those who do not. Some people see public broadcasting as an essential public good, but others consider it to be just one of the many options in the broadcasting industry. Because of these contrasting opinions, these two groups may differ in WTP for the subscription fee.

\section{Literature Review}

Intention to pay the subscription fee can vary with different perceptions because paying the subscription fee is an economic activity. Unfortunately, there has been no study focusing on perceptions or intentions of the public broadcasting audience who pay the subscription fee.

Willingness to Pay (WTP) is a way to measure the value of goods in monetary terms and has been adopted as a way of capturing consumer evaluation of goods and values in the field of behavioral economics (Green, 1992). This study focuses on WTP of the public for the public broadcasting subscription fee because public broadcasting is not a personal or private good for individuals to sell (Eom, 2008; Hanemann, 1991). Many studies have shown that WTP is an effective way to measure attitudes and intentions to buy goods in the form of explicitly visible and numerical expressions (Kahneman \& Ritov, 1994; Kahneman, Schkade, \& Sunstein, 1998; Payne et al., 2000). Valuations expressed in dollars are highly correlated with those expressed in rating scales frequently used as a way of measuring attitudes (Kahneman, Ritov, \& Schkade, 1999; Kahneman, Schkade, \& Sunstein, 1998; Payne et al., 2000).

Several studies examined viewer WTP for public broadcasting depending on demographic differences (e.g., Delaney \& O'Toole, 2004; Schwer \& Daneshvary, 1995); however, few studies have been conducted regarding viewer WTP according to perceptions about public broadcasting as a public good.

\subsection{WTP for the Subscription Fee of Public Broadcasting}

The value of public broadcasting is decided by viewer perceptions. If viewers no longer put exclusive public 
value on the public broadcasting channel, the subscription fee funding for public broadcasting may be negatively impacted. Although there have been few studies directly comparing public and private broadcasting in terms of WTP, there have been studies examining differences in WTP between public and private goods (Blaeij et al., 2003; Hultkrantz, Lindberg, \& Andersson, 2006; Johannesson, Johansson, \& O’Conor 1996; Svensson \& Johansson, 2010).

According to Green (1992), economic goods have more price elasticity of WTP than public goods. Price elasticity means that WTP decreases as price increases. In other words, public goods have less fluctuation in WTP than private goods. If the subscription fee for public broadcasting is increased, WTP decreases less when viewers perceive public broadcasting as a public good than when viewers perceive it as a private good.

The subscription fee is considered to be a kind of tax because every TV owner has to pay the fee, even if they do not watch the public broadcasting channel. WTP for the subscription fee is dependent on viewer perceptions as to whether or not they consider KBS to be a public good. We assume that there will be differences in WTP for public broadcasting between viewers who perceive it as public good and those who perceive it as a private good.

H1: The WTP for the subscription fee will differ between respondents who perceive KBS as public good and those who do not.

The public broadcasting company attempts to persuade viewers that the company makes many efforts to pursue its public role. Viewers who evaluate public value and the necessity of public broadcasting as more valuable tend to have greater willingness to pay the subscription fee rather than those who do not (Jeong \& Yoo, 2008; Kim, 2007). It can be assumed that WTP for the public broadcasting subscription fee depends on people's perceptions of how the company performs its public roles.

H2: Respondents who evaluate KBS as performing well in its public roles will show higher WTP for the subscription fee than those who do not.

\subsection{WTP and Framing}

In order to persuade people to agree with raising the subscription fee, effective communication strategies are needed. This study adopted the prospect theory suggested by Tversky and Kahneman. Specifically, the effects of message framing were tested. According to Tversky and Kahneman (1974), the anchoring effect occurs when different starting points yield different estimates, which are biased toward the initial values. When people evaluate the value of a good, they rely on an accessible value known as the "anchor" because of uncertainty and lack of information about the good. To evaluate the actual value of the good, people tend to adjust the value relative to the anchor. According to Mussweiler, Strack, and Pfeiffer (2000), the anchoring effect occurs because people selectively try to access knowledge which relates to the anchor. That is, when people hear the anchor, it stays in their head, and then people keep selectively accepting the information which has high relevance to the anchor.

Accordingly, it can be assumed that WTP for the subscription fee will differ depending on different anchor messages. If the anchoring message is lower than the current subscription fee, it is expected that people will feel a loss when they pay the subscription fee. If the anchoring message is higher than the current subscription fee, it is expected that people will feel a gain when they pay the subscription fee. It is important to determine which messages are associated with perceptions of gain or loss about the public broadcasting subscription fee. This study tested the following hypothesis to identify the effects of the anchoring messages on people's WTP for the subscription fee.

H3-1: Respondents who are exposed to a gain-framed message will show higher WTP for the subscription fee compared to those who are exposed to a loss-framed message or no message.

H3-2: Respondents who are exposed to a loss-framed message will show lower WTP for the subscription fee compared to those who are exposed to a gain-framed message or no message.

\section{Methods}

Procedure. An online quasi experiment was conducted from $9^{\text {th }}$ to $13^{\text {th }}$ November, 2012. A between-subject design was adopted. All samples were randomly distributed to each type of questionnaire. The independent variables were perception of public broadcasting as a public good and perception of public broadcasting's performance of public roles. The dependent variable was the intention of people to pay the subscription fee (i.e., WTP). 
Furthermore, for the third hypothesis, three types of questionnaires were used in this study to determine the effects of framed messages on intentions. One neutral message type and two forms of message questionnaires were used to suggest proper communication messages to raise intentions for the subscription fee. The independent variable was the message framed as a loss or a gain, and the dependent variable was the intention to pay the subscription fee.

Participants. The samples were gathered by quota sampling from panels of the online survey research company, Macromillembrain ${ }^{\mathrm{TM}}$. All respondents participated voluntarily without any incentives. In total, 252 respondents participated in the study, including 131 females (52\%) and 121 males (48\%). Mean age was 38.14 years $(S D=11.72)$ and mean monthly income was $\$ 4000$.

Messages. Three versions of the message were designed. The first version was a loss-framed message where respondents were influenced to perceive the subscription fee as a loss. The message contained information pointing out that the KBS subscription fee is $2500 \mathrm{KRW}$ per month (approximately USD 2), and that only KBS requires a mandatory subscription fee from viewers, whereas other territorial TV channels like the MBC (Munwha Broadcasting Company) and the SBS (Seoul Broadcasting System) do not require subscription fees from viewers and provide their services for free. This acts to cause respondents to perceive the KBS subscription fee as a loss because they are paying for a "free" service. The second version was a gain-framed message, which is a key message that the KBS currently emphasizes to persuade the public and justify a licensing fee increase. This message emphasized the point that KBS maintained its subscription fee at $2500 \mathrm{KRW}$ for 30 years despite economic inflation. In addition, KBS's subscription fee is much cheaper than other countries' public broadcasting subscription fee such as for the BBC and NHK. Although the subscription fee should be increased according to the inflation rate, like in other countries, the subscription fee of the KBS has been unchanged, which works to manipulate the respondents to see the fee as a gain. The third version, the control group, only contained a message that the subscription fee of KBS is currently $2500 \mathrm{KRW}$.

Measurements. Perceptions of public broadcasting as a public good involve whether or not people think that public broadcasting has characteristics which are distinctive from those of private goods. The present study constructed six questions: "KBS is a good that everyone can use"; "KBS is a good that has to be managed by collective costs rather than by private costs"; "KBS is a good that exists for public needs rather than private needs"; "KBS is a good that pursues socially collective welfare rather than individual welfare"; "KBS is a good that everyone can use even if an individual pays nothing"; and "KBS is a good that everyone can use at the same time”. All six questions were measured by a 5-point Likert-type scale (1: Not at all, 5: Absolutely yes). For the factor analysis, perceptions about public broadcasting as a public good were loaded into one factor, and the Cronbach's Alpha was 0.85. All six items were summated for the analysis $(M=4.08, S D=0.62)$.

Perceptions about the performance of public roles refer to whether people are satisfied with how KBS fulfills its responsibility for the public interest. Based on Kim's (2007) suggestions about 17 public values that public broadcasting performs, the present study asked people how well KBS fulfills these values: "KBS broadcasts programs to resolve social discrimination"; "KBS broadcasts programs for social integration"; "KBS broadcasts programs for the balanced development of local communities"; "KBS broadcasts programs compensating school education"; "KBS broadcasts programs for the development of scientific technology"; "KBS broadcasts programs to learn professional skills and knowledge"; "KBS broadcasts programs for improving the intellectual standards of citizens"; "KBS broadcasts programs for strengthening the ethics of citizens"; "KBS broadcasts programs to form proper family culture"; "KBS broadcasts programs to preserve and pass down traditional heritage for the future"; "KBS broadcasts programs for the diversification of opinions, ideas, and culture"; "KBS broadcasts programs to inform foreign culture"; "KBS broadcasts programs for wholesome entertainment"; "KBS broadcasts programs for providing credible global news and information"; "KBS broadcasts programs for a better international relationships"; "KBS broadcasts programs for liberal democracy"; and "KBS broadcasts programs to protect human rights". All of the questions were measured by a 5-point scale (1: Not at all, 5: Absolutely yes). In total, 17 items for measuring perceptions about public roles performance were analyzed and loaded into three factors. The first factor was named "social integration roles" and its Cronbach's alpha was 0.90. The second and third factors were named "cultural roles" (Cronbach's alpha $=0.82$ ) and "educational roles" (Cronbach's alpha $=0.82$ ), respectively.

WTP for the subscription fee refers to the amount of money people think is proper for the public broadcasting subscription fee. An open-ended question was asked, "How much money do you think is proper for the KBS subscription fee?” The mean WTP was $1648.02 \mathrm{KRW}(S D=1210.30)$. WTP ranged from $0.0 \mathrm{KRW}$ to 5000 
KRW.

Manipulation check. Each person exposed to the message framed as a loss or a gain was asked how they felt about the subscription fee. The results showed that $60 \%$ of respondents $(n=51)$ perceived the subscription fee as a loss when they were exposed to a loss-framed message, and $62 \%$ of respondents $(n=54)$ perceived the subscription fee as a gain or an appropriate price when they were exposed to a gain-framed message. Only the respondents who perceived the message as a loss or as a gain for each exposure were analyzed for the hypotheses tests.

\section{Results}

Hypothesis 1. Hypothesis 1 assumed that WTP for the subscription fee would differ between respondents who saw KBS as a public good and those who did not. A t-test was conducted to test H1. The result showed that respondents who saw KBS as a public good $(M=1815.38, S D=1604.23)$ had more willingness to pay the subscription fee than those who did not $(M=1443.17, S D=1111.88)\left[\mathrm{M}_{\text {diff }}=372.21, \mathrm{t}(249)=2.0, \mathrm{p}<0.05\right]$.

Hypothesis 2. Hypothesis 2 assumed that respondents who thought KBS performs its public roles well would be more willing to pay the subscription fee than those who did not. A t-test was conducted. The result showed that, the respondents who perceived that KBS performed its public roles well $(M=2055.96, S D=1666.02)$ showed more willingness to pay the subscription fee than those who did not $(M=1381.70, S D=1177.48)\left[M_{\text {diff }}\right.$ $=674.26, \mathrm{t}(249)=3.75, \mathrm{p}<0.001]$. More specifically, three factors' effects on WTP for the subscription fee were examined through a linear regression analysis. The result showed that only the role for culture was statistically significant (see Table 1 ).

Hypothesis 3. WTP for the subscription fee among three groups exposed to three different messages were examined through ANOVA. The results showed that there were statistically significant differences in WTP among the three groups. Respondents exposed to the gain-framed message $(M=2714.81, S D=137.62)$ showed more willingness to pay the subscription fee than respondents exposed to the loss-framed message $(M=435.29$, $S D=605.91)$ or to the control message $(M=1747.50, S D=949.61)[\mathrm{F}(2,248)=17.71, \mathrm{p}<0.001]$.

\section{Discussion}

This study aimed at examining different levels of intention to pay for public broadcasting services according to viewer perception of KBS as a public good. The results showed that respondents who consider KBS to be a public good rather than a private good were willing to pay more money for the service. Similar to electricity or the water system which are treated as essential public services, if KBS is perceived as an essential public service, the public will put up less resistance to a subscription fee increase. Due to the development of diverse telecommunication devices, a public broadcasting system like KBS becomes just one of many alternative choices among TV channels, which results in the perception that KBS is no longer a public service requiring payment. If public broadcasting needs the subscription fee to maintain its exclusive status, there needs to a clearer definition of its position in the broadcasting industry. KBS should inform people that public broadcasting is not a private good but an essential public good. Furthermore, public broadcasting is not just an alternative form of commercial TV.

In addition, respondents who felt that KBS performed its public role well were more willing to pay the subscription fee. Based on these results, persuasive messages need to include information detailing how the public broadcasting system fulfills its public roles of social integration, culture, and education. Facing governmental

Table 1. A regression analysis of factors of KBS's public roles with regard to WTP.

\begin{tabular}{|c|c|c|c|c|c|}
\hline \multirow{2}{*}{ Independent variables } & \multicolumn{2}{|c|}{ Unstandardized Coefficients } & \multirow{2}{*}{$\begin{array}{c}\text { Standardized Coefficients } \\
\text { Beta }\end{array}$} & \multirow{2}{*}{$t$} & \multirow{2}{*}{ Sig. } \\
\hline & B & Std. Error & & & \\
\hline (Constant) & -562.88 & 385.44 & & -1.46 & 0.145 \\
\hline Roles for social integration & 218.29 & 142.00 & 0.14 & 1.54 & 0.126 \\
\hline Roles for culture & 392.15 & 185.48 & 0.20 & 2.11 & $0.035^{*}$ \\
\hline Roles for education & 82.55 & 137.31 & 0.05 & 0.60 & 0.548 \\
\hline
\end{tabular}

$R^{2}=0.13$, adj- $R^{2}=0.12, F=12.35,{ }^{*} \mathrm{p}<0.05$. 
regulations on content and renewal evaluations for broadcasting service, many commercial TV channels are considering programs promoting education and social welfare in addition to entertainment. Because of this, the obvious distinction between the public broadcasting channel and commercial channels in terms of TV programming is disappearing. Accordingly, TV viewers do not currently attach much value to the public broadcasting channel as a public good. In addition, the linear regression analysis showed that the promotion of cultural values is the only statistically significant explanatory variable which raised intension to pay the subscription fee. Therefore, in order to increase the intention to pay the subscription fee, KBS needs to identify what public roles audiences expect from the public broadcasting channel. Based upon these expectations, KBS should put more effort into differentiating public broadcasting from commercial channels in terms of public roles and public interest achievements.

Through examination of Hypothesis 3, this study suggests communication strategies with which KBS should persuade its audiences that the subscription fee should be raised. The results showed that respondent willingness to pay the subscription fee differed depending on to which message they were exposed. Specifically, the lossframed message which set the anchoring point to zero by informing the audience that other territorial TV channels do not require viewers to pay the fee was found to decrease willingness to pay the subscription fee. This result also suggests that KBS is no longer uniquely identified as a public good and is thought of in the same way as commercial TV channels. Thus, TV viewers should be informed that KBS is not just one of many territorial TV channels but also performs distinctive and valuable public roles.

On the contrary, the gain-framed message setting the anchoring point for the subscription fee at that of overseas public broadcasting systems increased willingness to pay the subscription fee. Compared to other countries' subscription fees, KBS has kept the fee at $2500 \mathrm{KRW}$ (about \$2 US), despite an increasing inflation rate during 30 years, which primed respondents to view paying the subscription fee in Korea as a gain. Therefore, a persuasive message should emphasize that KBS has considered viewer economic situation over the last 30 years, but price rationalization has become inevitable in order to cope with global broadcasting industry challenges.

This paper has some important implications. First of all, this paper examined the perceptions of the public broadcasting system from the perspective of TV viewers, not from the perspective of policy makers or the broadcasting industry. This paper began by questioning whether TV viewers recognize the public broadcasting system as a real public good. Many studies have simply assumed that public broadcasting is a public good which uses the limited resources of the airwaves (Samuelson, 1954; Miansian, 1964). Second, WTP for the subscription fee illustrates that a price perception gap exists between KBS and viewers. Identifying the price gap between KBS and its viewers can help KBS to adopt appropriate price strategies to decrease public resistance against raising the subscription fee. The present study found that it is necessary to emphasize differences between the public broadcasting system and other territorial TV channels and the importance of rationalization of the subscription fee.

This paper also has some limitations. This paper did not examine the EBS (Educational Broadcasting System), which is the other public broadcasting system specializing in school education and lifelong education of citizens. KBS shares 3\% of the subscription fee with the EBS. According to Lim et al. (2011), EBS has contributed to drawing viewer interest, curiosity, and motivation to learn by offering high-quality educational content. If EBS were considered in this paper, the results of the factor analysis and its effects on WTP may have been different.

\section{References}

Blaeij, A. D., Florax, R. J., Rietveld, P., \& Verhoef, E. (2003). The Value of Statistical Life in Road Safety: A Meta-Analysis. Accident Analysis and Prevention, 35, 973-986. http://dx.doi.org/10.1016/S0001-4575(02)00105-7

Choe, J. (2010). The Horizontal Regulation Model and the Public Sector Broadcasting in the Ear of the Convergence of Broadcasting and Communications. Culture, Media, and Entertainment Law, 4, 27-54.

Delaney, L., \& O’Toole, F. (2004). Irish Public Service Broadcasting: A Contingent Valuation Analysis. The Economic and Social Review, 35, 321-350.

Eom, Y. (2008). Empirical Analysis on the Disparity between Willingness to Pay and Willingness to Accept for Drinking Water Risks: Using Experimental Market Methods. Environmental and Resource Economics Review, 17, $135-166$.

Green, D. P. (1992). The Price Elasticity of Mass Preferences. The American Political Science Review, 86, 128-148. http://dx.doi.org/10.2307/1964020

Hanemann, M. W. (1991). Willingness to Pay and Willingness to Accept: How Much Can They Differ? The American Eco- 
nomic Review, 81, 635-647.

Hultkrantz, L., Lindberg, G., \& Andersson, C. (2006). The Value of Improved Road Safety. Journal of Risk and Uncertainty, 32, 151-170. http://dx.doi.org/10.1007/s11166-006-8291-z

Jeong, H., \& Yoo, S. (2008). A Study on Public Value of Digital Broadcasting and Willingness to Pay of Media Audience. Korean Journal of Broadcasting, 22, 390-422.

Johannesson, M., Johansson, P., \& O’Connor, R. (1996). The Value of Private Safety versus the Value of Public Safety. Journal of Risk and Uncertainty, 13, 263-275. http://dx.doi.org/10.1007/BF00056156

Kahneman, D., \& Ritov, I. (1994). Determinants of Stated Willingness to Pay for Public Goods: A Study in the Headline Method. Journal of Risk and Uncertainty, 9, 5-38. http://dx.doi.org/10.1007/BF01073401

Kahneman, D., Ritov, I., Jacowitz, K. E., \& Grant, P. (1993). Stated Willingness to Pay for Public Goods: A Psychological Perspectives. Psychological Science, 4, 310-315. http://dx.doi.org/10.1111/j.1467-9280.1993.tb00570.x

Kahneman, D., Ritov, I., \& Schkade, D. (1999). Economic Preferences or Attitude Expressions?: An Analysis of Dollar Responses to Public Issues. Journal of Risk and Uncertainty, 19, 203-235. http://dx.doi.org/10.1023/A:1007835629236

Kahneman, D., Schkade, D., \& Sunstein, C. (1998). Shared Outrage and Erratic Awards: The Psychology of Punitive Damages. Journal of Risk and Uncertainty, 16, 49-86. http://dx.doi.org/10.1023/A:1007710408413

Kang, H. (2004a). Public Service Broadcasting Viewed by South Korean Newspapers. Korean Journal of Journalism \& Communication Studies, 48, 207-231.

Kang, H. (2004b). Theory of Public Broadcasting: Social Change of Korea and Public Broadcasting. Seoul, Korea: Nanam.

Kang, M. (2006). A Study on the Relationship between Willingness to Pay or Program Preference and Audience Welfare. Journal of Broadcasting Research, 63, 59-84.

Kim, C., \& Lee, W. (2010). A Study on Social Recognition of Public Broadcasting Subscription Fee. Korean Journal of Broadcasting, 24, 127-165.

Kim, J. (2007). A Study on the Relationship between the Recognition of Public Broadcasters on Public Values and Reception Fee. Korean Journal of Broadcasting, 21, 258-304.

Kim, Y. (2008). A Study on the Audience’s Understanding of the Identity of Public Broadcasting in the Digital Media Age. Journal of KSSSS, 16, 75-92.

Minasian, J. R. (1964). Television Pricing and the Theory of Public Goods. The Journal of Law and Economics, 71, 71-80. http://dx.doi.org/10.1086/466600

Mussweiler, T., Strack, F., \& Pfeiffer, T. (2000). Overcoming the Inevitable Anchoring Effect: Considering the Opposite Compensates for Selective Accessibility. Personality and Social Psychology Bulletin, 26, 1142-1150. http://dx.doi.org/10.1177/01461672002611010

Park, S. (2010). Positive Effects of Television Subscription Fees in Digital Age. Journal of Broadcasting Research, 70, 3659.

Payne, J. W., Schkade, D. A., Desvousges, W. H., \& Aultman, C. (2000). Valuation of Multiple Environmental Programs. Journal of Risk and Uncertainty, 21, 95-115. http://dx.doi.org/10.1023/A:1026573527618

Samuelson, P. A. (1954). The Pure Theory of Public Expenditure. The Review of Economics and Statistics, 36, 387-389. http://dx.doi.org/10.2307/1925895

Samuelson, P. A. (1958). Aspects of Public Expenditure Theories. The Review of Economics and Statistics, 40, 332-338. http://dx.doi.org/10.2307/1926336

Samuelson, P. A. (1964). Public Goods and Subscription TV: Correction of the Record. The Journal of Law and Economics, 81, 81-83. http://dx.doi.org/10.1086/466601

Schwer, K., \& Daneshvary, R. (1995). Willingness to Pay for Public Television and the Advent of "Look-like” Cable Television Channels: A Case Study. The Journal of Media Economics, 8, 95-109.

http://dx.doi.org/10.1207/s15327736me0803_2

Svensson, M., \& Johansson, M. V. (2010). Willing to Pay for Public Goods Road Safety in Stated Preference Studies: Why Difference? Accidental Analysis and Prevention, 42, 1205-1212. http://dx.doi.org/10.1207/s15327736me0803_2

Tversky, A., \& Kahneman, D. (1974). Judgment under Uncertainty: Heuristics and Biases. Science, 185, 1124-1131. http://dx.doi.org/10.1126/science.185.4157.1124 